\title{
0 empoderamento de mulheres no processo de ensino-aprendizagem de Inglês Instrumental: análise de interações em um grupo do WhatsApp durante a criação de uma propaganda de coletor menstrual
}

\author{
Women's empowerment in the process of teaching-learning ESP: \\ analysis of interactions in a WhatsApp group during the creation of a \\ menstrual cup advertisement
}

Vanessa Moreno Mota1

\begin{abstract}
Resumo
O processo de ensino-aprendizagem de Inglês Instrumental deve levar em consideração as necessidades dos estudantes (ROSSINI; BELMONTE, 2015), de forma que levem em consideração os aspectos socioculturais, para que eles possam se comunicar através de diferentes gêneros discursivos (ROJO; BARBOSA, 2015) em diferentes práticas sociais (MOITALOPES, 2006). Este artigo tem como objetivo discutir sobre o empoderamento das mulheres (BERTH, 2019; RIBEIRO, 2018; 2019), em Inglês Instrumental, durante a criação de uma propaganda antirracista e antissexista por três mulheres, que são estudantes de um curso técnico em Administração. Os dados foram gerados em um grupo do aplicativo WhatsApp, no qual as estudantes negociaram a criação da propaganda de uma marca de coletores menstruais chamada de "The Same". Os resultados apontam que o papel das mulheres na sociedade abordado em sala de aula, bem como o uso do WhatsApp — um espaço de afinidade (GEE; HAYES, 2012) —, contribuíram para que as estudantes pudessem elaborar uma propaganda de um coletor menstrual, que é uma alternativa aos absorventes descartáveis, que seja sustentável e libertadora para as mulheres (GAYBOR, 2019), de forma que possa contribuir para o direito à higiene menstrual e para o empoderamento feminino.
\end{abstract}

Palavras-chave: Empoderamento. Menstruação. Inglês.

\begin{abstract}
The English for Specific Purposes (ESP) teaching-learning process must take into consideration the students' needs (ROSSINI; BELMONTE, 2015), and also take into account sociocultural aspects, so that they can communicate through different discursive genres (ROJO; BARBOSA, 2015) in different social practices (MOITA-LOPES, 2006). This article aims to discuss the women's empowerment (BERTH, 2019; RIBEIRO, 2018; 2019), in ESP, during the creation of an anti-racist and anti-sexist advertisement by three women, who are students of a secondary level technical course in Administration. The data was collected in a WhatsApp group in which the students negotiated the creation of an advertisement for a menstrual cup brand called "The Same". The results show that the women's role in society discussed in the classroom, as well as the use of WhatsApp - an affinity space (GEE; HAYES, 2012) - , contributed to the students' ability to develop a menstrual cup advertisement, which is an alternative to disposable pads that is sustainable and liberating for women (GAYBOR, 2019), so that it can contribute to the right to menstrual hygiene and women's empowerment.
\end{abstract}

Keywords: Empowerment. Menstruation. English.

\footnotetext{
1 Doutoranda em Interdisciplinar em Linguística Aplicada. Instituto Federal de Educação, Ciência e Tecnologia do Rio de Janeiro - Campus Niterói, Niterói, Rio de Janeiro, Brasil. Orcid: https://orcid.org/0000-0002-2083-7567. E-mail: vanessa.mota@ifri.edu.br.
}

LínguaTec, Instituto Federal de Educação, Ciência e Tecnologia do Rio Grande do Sul, Bento Gonçalves v. 5 , n. 2, p. 208-226, nov. 2020. 


\section{Introdução}

Berth $(2019$, p. 52) nos diz que "indivíduos empoderados formam uma coletividade empoderada e uma coletividade empoderada, consequentemente, será formada por indivíduos com alto grau de recuperação da consciência do seu eu social, de suas implicações e agravantes". A partir desta constatação, podemos nos questionar se o ensino de línguas, em especial o de Inglês Instrumental2 ${ }^{2}$ é um instrumento para o empoderamento de estudantes.

É urgente que as aulas de línguas sejam espaços para a problematização de questões sociais, a fim de que se crie uma consciência crítica a respeito. Dessa forma, estaremos contribuindo para a transformação social (FREIRE, 2019 [1968]) tão necessária à prática pedagógica.

Este trabalho parte do pressuposto de que o empoderamento é pré-requisito para que haja uma agência transformativa nas práticas sociais dos indivíduos (STETSENKO, 2017; OSTERGA, 2018). Para tanto, sua proposta vai além do ensino com foco em questões gramaticais ou de leitura de textos escritos: buscou-se levantar o debate acerca do racismo e do sexismo presente em propagandas durante as aulas de Inglês Instrumental em um curso técnico em Administração, concomitante/subsequente ao Ensino Médio em um campus do Instituto Federal de Educação, Ciência e Tecnologia do Rio de Janeiro (doravante IFRJ), em paralelo à utilização de uma conta da rede social Instagram, com fins pedagógicos e de uso exclusivo dos estudantes dessa turma.

As novas tecnologias podem se tornar aliadas na educação linguística, visto que podemos utilizar os seus recursos disponíveis na elaboração de gêneros discursivos multimodais, como as propagandas, ao mesmo tempo que o processo de elaboração passa por uma negociação entre pares, mediados pela linguagem (SILVA; ROCHA, 2017; MOTA, 2017, entre outros). Com base nisso, os dados desta pesquisa focalizam na interação entre três estudantes mulheres e as suas percepções e negociações sobre a elaboração de uma propaganda em língua inglesa de um coletor menstrual de uma marca fictícia criada por elas, intitulada de "The Same", em um grupo do aplicativo WhatsApp.

\section{A educação linguística feminista de Inglês Instrumental}

O ensino-aprendizagem de Inglês Instrumental, ou Inglês para Fins Específicos (do inglês, English for Specific Purposes), apresenta uma trajetória na qual é comumente associado ao ensino de leitura, muitas vezes sendo considerada monótona. Ele carrega, em sua abordagem, alguns mitos, tais como a impossibilidade de uso de dicionários e do ensino de gramática em sala, bem como a crença de

\footnotetext{
2 Inglês Instrumental é o nome da disciplina ministrada, foco desta pesquisa, cujo objetivo é em ensino de leitura, segundo a ementa.
} 
que estudantes com baixa proficiência no idioma não conseguiriam acompanhar essa aula. Outro mito seria a sua aplicação apenas no nível técnico, o que exclui outros contextos educacionais que poderiam ser contemplados com essa abordagem (RAMOS, 2005; ROSSINI; BELMONTE, 2015).

Rossini e Belmonte (2015) nos lembram que a base para uma abordagem instrumental do ensino-aprendizagem de inglês é o foco nas necessidades dos alunos, considerando os aspectos socioculturais envolvidos no processo e que vão além da exploração e da decodificação de textos (leitura). Isto nos levaria a uma abordagem que considere o trabalho com os gêneros discursivos, uma vez que estes são caracterizados como "entidades que funcionam em nossa vida cotidiana ou pública, para nos comunicar e para interagir com as outras pessoas" (ROJO; BARBOSA, 2015, p. 16). Assim, podemos entender que, com o advento de novas tecnologias, novos gêneros vão surgindo: blogs, chats, posts, entre outros.

Quais seriam, pois, as reais necessidades de estudantes da segunda década dos anos 2000 ao se aprender a língua inglesa, de forma instrumental? O foco em leitura, aparentemente, não supre com todas elas, em um momento em que se identifica a urgência de se trabalhar com os mais variados gêneros discursivos, especialmente, aqueles que emergem no meio virtual e com características multimodais. Rossini e Belmonte (2015) destacam o papel desafiador e relevante das novas tecnologias no ensino-aprendizagem de inglês instrumental, "de forma a se adequar às demandas de ensinoaprendizagem atuais seja em cursos no modelo a distância ou semi-presenciais" (p. 357).

Em um período durante e pós-pandemia de COVID-19, no qual encontramos mulheres, em sua maioria, na linha de frente ao seu combate ${ }^{3}$, as aulas síncronas e assíncronas de inglês precisam considerar e problematizar esses dados, que refletem uma sociedade que ainda possui muita desigualdade e outras temáticas que, por limitações de espaço, não serão abordadas neste artigo, mas que demandam pesquisas e ações que os tragam para o debate na formação linguística discente, com base em Ribeiro (2019): encarceramento, racismo estrutural, branquitude, lesbiandades, mulheres indígenas, transexualidade, afetividade, interseccionalidade e masculinidades.

Tais temáticas nas aulas de línguas, em especial de Inglês Instrumental ${ }^{4}$ - foco deste artigo -, contribuem para uma educação linguística crítica de educandos, ao problematizar questões pertinentes à vida em sociedade. Essa abordagem se aproxima da concepção de linguagem como uma prática social, que considera os sujeitos envolvidos no processo de ensino-aprendizagem como heterogêneos e

\footnotetext{
3 Disponível em: <https://nacoesunidas.org/mulheres-na-linhas-de-frente-da-covid-19/>. Acesso em 19 set. 2020.

${ }^{4} \mathrm{O}$ trabalho com temáticas referentes aos usos autênticos de inglês na referida disciplina busca promover a discussão e prática sobre a língua-alvo, a partir das necessidades dos estudantes e que estejam voltadas para o ramo da Administração, diferentemente de uma disciplina regular, que teria um foco mais abrangente.
} 
que interagem mediados pela linguagem, nas quais estão imbricadas múltiplas identidades em construção, desigualdades, entre outros (MOITA-LOPES, 2006).

Além de considerar os aspectos sócio-históricos, a educação linguística deve se aproximar do que Freire (2019 [1968]) defende como uma práxis (reflexão e ação) para a transformação do mundo. Segundo o autor, "inserção crítica e ação são as mesmas coisas" (p. 53). Dessa forma, uma educação linguística que se proponha a fomentar a criticidade em busca de transformação social necessita promover o debate sobre as situações sócio-históricas do alunado e de outros contextos não explorados nas aulas e incentivá-los a agirem no mundo.

Agir no mundo em busca de transformá-lo para uma melhor vivência em sociedade pode começar nas aulas de línguas, a partir do empoderamento de estudantes. Empoderar vem do inglês empower, que, em linhas gerais, significa "dar poder". Entretanto, a concepção de empoderamento no ensino-aprendizagem de Inglês Instrumental, defendida neste trabalho, se aproxima do postulado por Berth (2019), que defende que empoderar seria fornecer estratégias para a "libertação individual a serviço da emancipação coletiva" (BERTH, 2019, p. 25). Para a autora, tais estratégias demandam posturas que sejam "antirracistas, antissexistas e anticapitalistas" e que considerem as "articulações políticas de dominação que essas condições representam" (p. 51).

Osterga (2018) acredita que o empoderamento é um pré-requisito para a agência transformativa, que se caracterizaria como um processo no qual os sujeitos, agentes das suas próprias histórias e comunidades, moldariam e criariam o "seu mundo, seu futuro e seu próprio desenvolvimento enquanto contam com os recursos sociais e culturais" (STETSENKO, 2017, p. 80) na co-construção das suas identidades e práticas sociais.

A concepção de empoderamento defendida neste trabalho não se desvincula dos pressupostos sobre a consciência crítica de Paulo Freire. Somente a partir de uma práxis libertadora, isto é, a ação e reflexão sobre a sua prática, poderemos transformar o mundo. Freire (2019 [1968]) nos lembra que a superação da dualidade oprimidos-opressores, aqui, neste trabalho, traduzida como uma busca da superação de atitudes racistas e sexistas contra as mulheres, "exige a inserção crítica dos oprimidos na realidade opressora, com que, objetivando-a, simultaneamente atuam sobre ela" (p. 53). Dessa forma, uma educação linguística que busque a transformação social deve promover mais do que a agência em educadores e educandos, isto é, deve promover a práxis, que englobaria um posicionamento ativista com reflexão sobre as práticas sociais.

A seguir, apresento um gráfico-resumo que relaciona os conceitos de empoderamento, práxis (que englobaria a agência transformativa com reflexão), de modo que sejam enxergados como um 
processo em busca da transformação social, especialmente em ambiente educativos, como a escola. Sabemos que as práticas sociais sofrem interferências oriundas de diferentes esferas e que os processos educacionais, dificilmente, acontecem de modo linear, porém, no esquema a seguir, apresento como seria a conjugação das teorias de Berth (2019), Osterga (2018), Stetsenko (2017) e Freire (2019 [1968]), de modo ideal: o empoderamento como sendo propulsor da práxis e cujo resultado seria a transformação social, em uma educação linguística feminista.

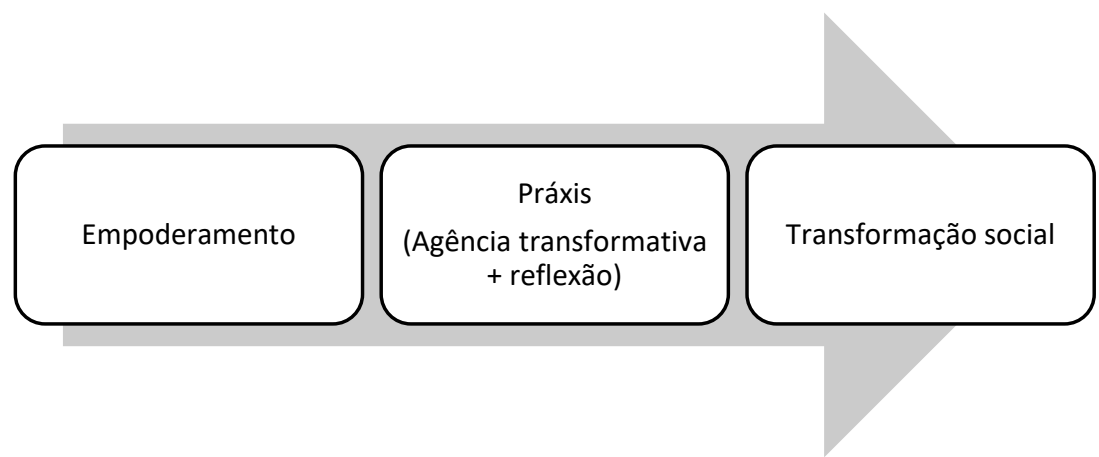

Figura 1. Relação processual entre empoderamento, práxis e transformação social na educação linguística feminista. Fonte: Autoria própria, com base em Berth (2019), Osterga (2018), Stetsenko (2017) e Freire (2019 [1968]).

Apoio-me em Hooks (2015) que defende que a educação feminista contribui para a consciência crítica. Em suma, a autora defende que o feminismo é para todo mundo e que contribui para eliminar diferentes tipos de exploração e opressões, a partir da consciência crítica ${ }^{5}$. Portanto, trago para a minha experiência como docente de língua inglesa esses pressupostos, em busca de uma educação linguística feminista, que promova a conscientização crítica de discentes acerca das diferentes desigualdades existentes, em especial o racismo e o sexismo.

Logo, uma educação linguística que se considere feminista, na luta, especialmente, antirracista e antissexista - focos deste trabalho -, deve se pautar em identificar situações de opressão no cotidiano e buscar atuar da seguinte forma, segundo Ribeiro (2018):

\footnotetext{
Se for professora, a mulher pode estar atenta aos xingamentos machistas muitas vezes naturalizados como brincadeiras ou chacotas de crianças. Tentar promover discussões em salas de aula que levem à reflexão sobre a situação das mulheres. Criar um grupo na comunidade ou associação do bairro para discutir estratégias de apoio a outras mulheres ou o enfrentamento da violência que possam vir a sofrer (RIBEIRO, 2018, p. 136).
}

\footnotetext{
5 É importante destacar que, no que concerne à consciência crítica, que muito se relaciona Freire (2019 [1968]), Hooks (2017) afirma que "Freire tem de lembrar os leitores de que ele nunca falou da conscientização como um fim em si, mas sempre na medida em que se soma à práxis significativa (p. 68)".
} 
Na próxima seção, apresento como as novas tecnologias digitais podem ser aliadas no empoderamento feminino e na educação linguística feminista, especialmente, com o uso do aplicativo de bate-papo WhatsApp, e discorro sobre os espaços de afinidade criados em ambientes virtuais como este.

\section{0 aplicativo WhatsApp como um espaço de afinidade}

Smartphones, aplicativos, streaming ${ }^{6} . .$. muitas são as nomenclaturas que se tornaram bastante populares nos últimos anos e que se relacionam, especialmente, com as tecnologias móveis.

Ao tratarmos sobre o ensino-aprendizagem de línguas, especialmente de língua inglesa, estes termos podem ser explicados e a utilização desses recursos podem ser incentivados, a depender da disponibilidade de cada contexto educacional. Assim, espera-se que os estudantes tenham maior contato com as novas Tecnologias Digitais da Informação e Comunicação (doravante TDICs) e saibam utilizálas de maneira autônoma tanto dentro, quanto fora da sala de aula.

Santaella (2007), há mais de uma década, chamava de "quinta geração tecnológica" a geração de tecnologia contínua, isto é, a que vivemos em 2020, que se caracteriza dessa forma a partir da difusão das tecnologias móveis (smartphones, aplicativos, entre outros). Esta geração surge após aquelas voltadas para o rádio e TV (eletroeletrônicas), dentre outras mais obsoletas. De acordo com Rojo e Moura (2019, p. 36), "passamos então das telas de cinema e TV para as fitas VHS alugadas em locadoras e para o streaming de vídeo em computadores e laptops e para as telas de HDTV digital, tablets ou celulares, onde podemos escolher na Netflix o filme a que queremos assistir".

Apesar dessas novas tecnologias estarem, teoricamente, ao alcance de todos, ainda há evidências de uma grande desigualdade no Brasil com relação ao acesso às TDICs por estudantes de escolas públicas. Uma pesquisa sobre sobre conectividade aponta que cerca de $40 \%$ dos estudantes da rede pública de ensino não possuem computador e nem tablet em casa. Assim, muitos ainda dependem exclusivamente do celular para terem acesso à Internet ${ }^{7}$.

Apesar disso, dados indicam que a finalidade da conectividade tem alavancado um posicionamento ativista nas redes sociais, com atenção especial ao ativismo feminista ${ }^{8}$ (LANGNER et

\footnotetext{
${ }^{6}$ Segundo o site Technoblog, streaming é "a tecnologia de transmissão de dados pela internet, principalmente áudio e vídeo, sem a necessidade de baixar o conteúdo. 0 arquivo, que pode ser um vídeo ou uma música, é acessado pelo usuário online. O detentor do conteúdo transmite a música ou filme pela internet e esse material não ocupa espaço no computador ou no celular. Algumas plataformas oferecem o download de faixas, apenas para assinantes.". Disponível em: $<$ https://tecnoblog.net/290028/o-que-e-streaming/>. Acesso em 16 set. 2020.

7 Disponivel em: <https://g1.globo.com/educacao/noticia/2020/06/09/quase-40percent-dos-alunos-de-escolas-publicas-naotem-computador-ou-tablet-em-casa-aponta-estudo.ghtml>. Acesso em 16 set. 2020.

8 Entendo, pois que o movimento feminista é plural, com diferentes vertentes, porém que buscam questionar o mundo patriarcal e conservador. Nas palavras de Tiburi (2019, p. 43), "O feminismo, vamos insistir nisso, mais do que uma teoria e
} 
al., 2015). Lima e De Grande (2013) apontavam a discussão sobre a questão da mulher nas diferentes mídias, como os blogs, e em como a escola precisaria considerar essas tecnologias, para ir além do trabalho com o texto escrito:

Em um país com milhões de não alfabetizados como o Brasil e de concentração de renda absurda, os acessos e posicionamento crítico em relação às diversidades que compõem nosso atual período histórico-cultural precisam adentrar a escola, principal agência de letramento de nossa sociedade. É preciso que a escola prepare a população para um funcionamento da sociedade cada vez mais digital e também para buscar no ciberespaço um lugar para se encontrar, de maneira crítica, com diferenças e identidades múltiplas (LIMA; DE GRANDE, 2013, p. 58).

Entretanto, como pensar e implementar tais recursos em contextos educacionais diversos e heterogêneos, alguns sem uma gama de recursos tecnológicos disponíveis? O presente trabalho, situado em um campus do IFRJ, busca apresentar a solução encontrada por três estudantes de um curso técnico em Administração na elaboração de uma propaganda em inglês, contando com tecnologias próprias de conectividade, inclusive com o uso voluntário de um grupo do aplicativo de bate-papo WhatsApp. A seguir, apresento os principais recursos disponíveis neste aplicativo e suas respectivas descrições:

\begin{tabular}{|l|l|}
\hline Envio e recebimento de mensagens de texto & $\begin{array}{l}\text { As mensagens enviadas não são tarifadas no plano do } \\
\text { celular, é necessário apenas conexão de Internet. }\end{array}$ \\
\hline Criação e gerenciamento de grupos & $\begin{array}{l}\text { Os grupos podem conter até } 256 \text { pessoas e é possível } \\
\text { compartilhar fotos, vídeos e mensagens. }\end{array}$ \\
\hline Chamadas de voz e vídeo & $\begin{array}{l}\text { Com as chamadas de voz e vídeo gratuitas, não é preciso } \\
\text { gastar os minutos do plano do celular. }\end{array}$ \\
\hline $\begin{array}{l}\text { Envio e recebimento de áudios, fotos, vídeos, gifs }{ }^{9}, \\
\text { figurinhas e documentos (.pptx, .docx, entre outros) }\end{array}$ & $\begin{array}{l}\text { Tira fotos e grava vídeos diretamente do aplicativo, sem } \\
\text { necessidade de abrir a câmera, e da galeria do celular; } \\
\text { envio e recebimento de arquivos, tais como .docx, .pptx, } \\
\text {.pdf, entre outros; envio e recebimento de imagens em } \\
\text { movimento (gifs) ou imagens estáticas (figurinhas). }\end{array}$ \\
\hline Atualização de status & $\begin{array}{l}\text { Possibilidade de compartilhar fotos, vídeos e textos no } \\
\text { status, com duração de } 24 \text { horas para acesso de acordo } \\
\text { com as permissões: contatos do celular ou público em geral. }\end{array}$ \\
\cline { 1 - 2 }
\end{tabular}

Quadro 1. Recursos disponíveis no aplicativo WhatsApp e suas respectivas descrições.

Fonte: Adaptado de MOTA, 2017.

uma prática intimamente enlaçadas, é a invenção de um outro mundo possível, a partir da desmontagem do jogo patriarcal, mas apenas enquanto a invenção de um outro mundo constitui sua utopia".

9 O gif é uma junção de imagens que podem ser estáticas ou não, mas que formam uma animação. Não possuem som, portanto não podem ser confundidas com vídeos. Disponível em: <https://canaltech.com.br/software/o-que-e-gif-e-como-usalo/>. Acesso em 19 set. 2020.

LínguaTec, Instituto Federal de Educação, Ciência e Tecnologia do Rio Grande do Sul, Bento Gonçalves 
Adicionalmente, com o uso cada vez mais popular do aplicativo WhatsApp, seja para usos pessoais, educativos e até mesmo profissionais, destaco a possibilidade de este ser considerado um dos mais atuais espaços de afinidade (GEE; HAYES, 2012), o qual é possível criar grupos para trocas de informações e resoluções de problemas, de maneira rápida e eficaz, como apontam os dados desta pesquisa (ver Seção 5). Ademais, o WhatsApp também tem se apresentado como um aliado na educação, em especial, no ensino-aprendizagem de línguas (SILVA; ROCHA, 2017; MOTA, 2017, entre outros).

Para o WhatsApp ser considerado um espaço de afinidade, trago o conceito de Gee e Hayes (2012), originalmente atrelado aos jogos virtuais. Para conseguir macetes, pontos ou até mesmo passar de fases, os jogadores costumam utilizar sites e fóruns on-line. Nessas ferramentas tecnológicas, os membros possuem afinidades semelhantes e podem encontrar ajuda mútua para alcançar os seus objetivos. Os autores apontam que

\begin{abstract}
Espaços de afinidade e outros tipos de comunidade podem dar às pessoas um sentimento de pertença, mas também podem dar às pessoas um senso de "nós" (os internos) contra "eles" (os estranhos). As pessoas podem cooperar nesses espaços e comunidades, mas também podem competir ferozmente por status. Eles podem se comunicar educadamente e de forma amigável ou podem se envolver em uma interação hostil e insultuosa (que é tão difundida que um termo distinto, "flamejante" agora é usado para descrevê-lo) (p. 7).
\end{abstract}

Ademais, para um site ou aplicativo ser considerado um espaço de afinidade, é necessário identificar algumas características neles, integralmente ou parcialmente. Com base nos estudos de Gee e Hayes (2012), aponto alguns destaques que se aproximam dos dados desta pesquisa:

\begin{tabular}{|rl|}
\hline 1. & Os espaços de afinidade não são separados por idade. \\
\hline 2. & Todos podem, se quiserem, produzir e não apenas consumir. \\
\hline 3. & O conteúdo é transformado pela interação. \\
\hline 4. & Há diferentes forma e rotas para a participação. \\
\hline 5. & Liderança é porosa. \\
\hline 6. & As pessoas obtêm incentivo do público e feedback dos colegas, embora todos desempenhem os \\
& dois papéis em momentos diferentes \\
\hline
\end{tabular}

Quadro 2. Características dos Espaços de Afinidade Fonte: Adaptado de GEE e HAYES, 2012.

Por se tratar de um aplicativo de bate-papo gratuito, de uso da internet ilimitada, a depender do plano da operadora de celular, bem como, possuir recursos que facilitem a comunicação síncrona e assíncrona de usuários, o WhatsApp permite que as pessoas se engajem em grupos de afinidade mútua, 
compartilhando textos multimodais e, assim, aumenta o sentimento de pertença entre os interactantes. Discorro sobre essa questão na Seção 5 , na qual analiso as interações ocorridas entre três estudantes mulheres de um curso técnico em Administração em um grupo do WhatsApp. Na próxima seção, apresento a metodologia desta pesquisa e detalho as participantes envolvidas.

\section{Metodologia}

Esta pesquisa se caracteriza por ter uma abordagem qualitativa e de cunho etnográfico, devido à ênfase no processo de aprendizagem, mais especificamente, na resolução de uma tarefa de casa avaliativa da disciplina de Inglês Instrumental, ao invés do foco no resultado (GERHARDT; SILVEIRA, 2009). Ainda, apresento, brevemente, a visão das participantes sobre a pesquisa.

Para geração de dados, foram utilizados: a) um questionário do Google Forms, divulgado no início do semestre letivo, a fim de mapear o acesso aos recursos tecnológicos dos estudantes de uma turma do curso técnico em Administração concomitante/subsequente ao Ensino Médio; b) prints da conversa de um grupo de WhatsApp com três estudantes mulheres desta turma e c) gravação de uma entrevista com as participantes da pesquisa, após a geração de dados do primeiro semestre letivo de 2019.

Nas próximas subseções, apresento o contexto no qual esta pesquisa foi desenvolvida (Subseção 4.1.) e as informações básicas sobre as participantes voluntárias (Subseção 4.2.).

\subsection{0 contexto de pesquisa}

Esta pesquisa foi desenvolvida em uma turma de um curso técnico em Administração concomitante/subsequente ao Ensino Médio, durante o primeiro semestre letivo de 2019, em um campus em implantação do IFRJ. Por estar em fase de implantação, à época, não havia computadores com acesso à Internet em alta velocidade para a utilização durante as aulas. Sendo assim, optou-se por focar a pesquisa na utilização de dispositivos móveis dos próprios estudantes.

A disciplina ofertada para esta turma pesquisada foi Inglês Instrumental, incluída apenas no primeiro período da grade do referido curso e possui uma carga horária total de 54 horas/semestre.

Por ser um curso da área administrativa ofertado no período vespertino, este possui um índice considerável de evasão, que necessita de um estudo mais aprofundado para entender as causas. Entretanto, a partir de relatos, entende-se que alguns dos fatores que contribuem para a evasão de estudantes sejam: a) o fato de o horário do curso ser em horário comercial, logo, aquelas/aqueles que 
conseguem um emprego, não conseguem conciliar com os estudos e b) dificuldades de conseguir o passe livre nos ônibus, o que prejudica a locomoção de estudantes até o campus ${ }^{10}$.

$\mathrm{Na}$ próxima subseção, apresento as estudantes focadas nesta pesquisa. Por limitações de espaço, foi necessário um recorte desta pesquisa, o que inviabiliza a análise da participação do restante da turma neste artigo.

\subsection{As participantes da pesquisa}

Buscando seguir as Normas das Resoluções CNS n 466/12 e n 510/16, no que concerne a Ética em Pesquisa, o projeto "Uso de tecnologias no ensino técnico" foi submetido ao Conselho De Ética do Instituto no qual esta pesquisa foi desenvolvida e obteve aprovação para ser desenvolvido.

Como toda pesquisa que envolve seres humanos necessita de aprovação de um comitê de ética, não poderia deixar de destacar o desafio de submissão deste projeto, por ser um processo burocrático originário da área da saúde, com caraterísticas bioéticas e biomédicas (GARCEZ, 2015), mesmo sendo uma pesquisa da Linguística Aplicada.

Após aprovação pelo Conselho de Ética, a proposta de pesquisa a ser desenvolvida na Turma $A^{11}$ foi apresentada à turma cursista do primeiro período do curso técnico em Administração, na disciplina de Inglês Instrumental e, em seguida, aquelas/aqueles que gostariam de ser voluntários autorizaram a geração de dados, que ocorreu ao longo do primeiro semestre letivo de 2019.

Ao todo, neste artigo, analiso a participação das seguintes estudantes: Jéssica, Débora e Diva $^{12},{ }^{13}$, ocorrida, especialmente, em um grupo do WhatsApp criado voluntariamente por elas. No início do semestre letivo de 2019, foi enviado aos estudantes desta turma um questionário, via Google Forms, a fim de traçar um perfil deles. Assim, temos como resultado os seguintes dados das participantes:

\footnotetext{
10 Havia, na época de geração dos dados desta pesquisa, a discussão sobre a disponibilidade de passe livre para estudantes de cursos técnicos concomitantes ao Ensino Médio, que foi aprovada pela Lei 8.202/18 pela Assembleia Legislativa do Estado do Rio (Alerj), mas que foi julgada pelo Tribunal de Justiça do Estado do Rio (TJ-RJ) como inconstitucional. Disponível em: <https://cliquediario.com.br/politica/alerj-anuncia-que-vai-recorrer-de-decisao-do-tj-rj-que-suspendeu-lei-estadual-do-passelivre-para-universitarios>. Acesso em 19 set 2020.

11 Nome da turma fictício.

12 Todos os nomes são fictícios, a fim de preservar as identidades das participantes.

13 Conforme já informado, neste artigo, há um recorte desta pesquisa, que visa investigar o uso de tecnologias no ensino técnico. A escolha das participantes desta pesquisa justifica-se pela proatividade identificada em sala de aula nelas e o senso de coletividade apresentado por elas, o que me despertou a atenção, como professora da turma e pesquisadora.
} 


\begin{tabular}{|l|l|l|l|}
\hline Nome & Idade & $\begin{array}{l}\text { Quais aparelhos costuma ter } \\
\text { acesso à internet? }\end{array}$ & $\begin{array}{l}\text { Quais instrumentos pretende usar para estudar } \\
\text { na disciplina de inglês instrumental? }\end{array}$ \\
\hline Jéssica & 18 anos & Celular e computador & Dicionários, Instagram e WhatsApp \\
\hline Débora & 39 anos & Celular e notebook & Livros, aplicativos e Netflix \\
\hline Diva & 20 anos & Celular & Livros, dicionários, aplicativos e YouTube \\
\hline
\end{tabular}

Quadro 3. Informações das estudantes participantes.

Fonte: Autoria própria.

Conforme os resultados do questionários nos apontam, o uso de celular era o ponto em comum das estudantes voluntárias da pesquisa, o que indica um fator que possa ter contribuído para a utilização de um grupo do WhatsApp criado voluntariamente por elas, para a resolução de uma tarefa de casa avaliativa de Inglês Instrumental. Durante o semestre letivo - período de geração dos dados desta pesquisa -, nenhuma participante evadiu o curso. Além disso, todas finalizaram e/ou continuaram os estudos no curso técnico em Administração, até o momento da escrita deste artigo.

Os dados também apontam uma heterogeneidade entre as participantes, algo bastante comum no perfil de estudantes desse curso: é um curso que abrange estudantes de diferentes idades, a partir dos 16 anos, e com diferentes acessos aos recursos tecnológicos.

Na próxima seção, apresento e analiso os dados gerados nesta pesquisa realizada no primeiro semestre de 2019, com foco nas interações ocorridas no grupo de WhatsApp criado por estas estudantes, de uma turma do curso técnico em Administração, do período vespertino. As interações analisadas relacionam-se à resolução de uma tarefa de casa avaliativa de inglês instrumental, que se referia à criação de uma propaganda não sexista e não racista de uma empresa fictícia criada pelas integrantes do grupo, em celebração ao mês da mulher, no mês de março de 2019.

\section{Análise de dados}

Nesta seção, analiso parte das interações ocorridas em um grupo de WhatsApp de três estudantes mulheres de um curso técnico em Administração em um campus do IFRJ Este grupo foi criado de maneira voluntária e, inicialmente, era intitulado "English Group - ADM/IFRJ", cujas integrantes eram Jéssica, Diva e Débora, conforme indicado na Subseção 4.2.

Paralelo a este grupo do WhatsApp, elas, juntamente com os demais estudantes da turma, seguiam e tinham acesso a uma conta do Instagram criada com fins pedagógicos para a disciplina de Inglês Instrumental. Nesta conta, os estudantes deveriam postar as atividades solicitadas ao longo do semestre letivo (2019.1), de modo individual ou em grupo. Para este artigo, vamos nos ater aos caminhos 
percorridos pelas estudantes supracitadas na resolução de uma tarefa avaliativa, que consistia em criar uma propaganda de uma empresa fictícia criada pelo grupo. Como critérios a serem seguidos, temos: a) pensar e criar uma marca fictícia; b) elaborar uma propaganda para esta marca, a ser postada na conta do Instagram da turma, considerando o seu público-alvo fictício e c) o uso da língua inglesa. Dessa forma, Jéssica, Débora e Diva resolveram criar uma marca de coletor menstrual intitulada "The Same"14.

Como se trata de um curso técnico em Administração, o trabalho desenvolvido em sala de aula apontou algumas problemáticas existentes em propagandas já produzidas por grandes marcas, como 0 sexismo e o racismo. No que concerne as questões léxico-gramaticais, focalizou-se no uso de imperativos, corriqueiramente encontrados nesse gênero discursivo. Ademais, o uso do imperativo também é visto nas instruções de uso de alguns produtos, justificando-se, portanto, a escolha desse modo verbal para essa atividade avaliativa.

Além dos critérios de avaliação mencionados anteriormente, para a elaboração das postagens dos grupos, em consonância à celebração do mês da mulher (março/2019), as propagandas, em língua inglesa, também deveriam: a) respeitar os direitos humanos (DECLARAÇÃO UNIVERSAL DOS DIREITOS HUMANOS, 1948); b) valorizar as mulheres, inclusive as negras, a fim de se ter uma propaganda antissexista e antirracista; c) considerar o prazo de entrega (04/04/2019) e d) usar o inglês tanto na imagem, quando na legenda da postagem no Instagram.

Conforme já mencionado, o grupo formado pelas participantes Débora, Jéssica e Diva optou por criar uma empresa de coletores menstruais, "The Same". Durante entrevista grupal realizada, após o término do primeiro semestre, a estudante Jéssica aponta que o WhatsApp foi um auxílio complementar da negociação sobre a tarefa iniciada em sala de aula, conforme o Quadro 4. Assim, entendemos que, embora as estudantes estivessem sendo avaliadas por suas criações na conta do Instagram, o uso do WhatsApp foi escolhido voluntariamente para mediar a negociação da montagem dessas postagens.

Jéssica: a ideia foi aqui [sala de aula], mas o desenvolvimento foi no WhatsApp.

Vanessa: Bacana.

Quadro 4. Excerto de entrevista realizada após o semestre letivo de Inglês Instrumental (Agosto/2019). Fonte: Autoria própria.

\footnotetext{
14 Trabalhamos em sala de aula sobre o papel das mulheres na sociedade, com foco no debate das questões sexistas e racistas presentes em propagandas. Na proposta de atividade avaliativa, a escolha do produto, do público-alvo e da marca fictícios ficaram a critério de cada grupo. Vale ressaltar que não abordamos a questão ecológica em sala de aula, o que demonstra que esse tema foi um acréscimo voluntário por parte das alunas Jéssica, Diva e Débora, ao tratarem sobre um coletor menstrual. Por conta disso, não trabalhamos com o vocabulário específico relacionado aos coletores menstruais, 0 que pode indicar alguns possíveis equívocos de tradução, ao utilizarem "collector", no lugar de "cup", em referência ao coletor menstrual (Cf. Figura 7).
} 
Entendo que essa escolha se aproxime da facilidade de recursos e acessos que este aplicativo proporciona aos seus usuários, como o compartilhamento de fotos, vídeos, links, áudios e a possibilidade de uso de modo ilimitado, segundo alguns pacotes de dados móveis disponíveis em algumas operadoras de celular ${ }^{15}$. Além disso, as respostas ao questionário (ver Quadro 3), nos indicam que todas tinham acesso a um celular. Veremos, ao longo dessa análise, alguns trechos encontrados nesse grupo, cujos prints $^{16}$ foram cedidos gentilmente pelas participantes da pesquisa.

No início da negociação sobre a propaganda da marca fictícia de coletores menstruais "The Same", ocorrida no grupo de WhatsApp, identificamos uma preocupação com a questão da sustentabilidade na higiene menstrual, além da questão econômica envolvida, apontada pela Débora, conforme Figura 2.

\begin{tabular}{|l|}
\hline Débora \\
acho que a gente pode colocar \\
a questão da sustentabilidade... \\
que acham?
\end{tabular}

Figura 2. Excerto da fala da Débora sobre sustentabilidade, em 02/04/2019.

Fonte: Autoria própria, baseada na conversa do grupo do WhatsApp.

O uso de alternativas que sejam reutilizáveis e ecologicamente sustentáveis ${ }^{17}$ aos absorventes descartáveis, como os coletores, os discos e as calcinhas menstruais, se encaixam na questão de saúde e gerenciamento menstrual de pessoas que menstruam (mulheres cis e homens trans, por exemplo) e, juntamente com o chamado "ativismo menstrual", contribuem para validar esta que é uma temática referente a um direito humano (GAYBOR, 2019) e de empoderamento (BERTH, 2019).

Após Diva compartilhar a primeira versão da postagem, Débora sugere que a legenda trate sobre a sustentabilidade envolvida no uso de coletores menstruais e busca a opinião das demais colegas (ver Figura 1). Destaco que, embora Diva esteja no papel de par mais experiente ${ }^{18}$ na elaboração da imagem

\footnotetext{
15 Disponivel em: <https://podecomparar.com.br/telecom/celular/whatsapp-gratis>. Acesso em 19 set. 2020.

${ }_{16}$ Print ou print screen é uma captura de tela feita em smartphones.

17 Segundo 0 site "Impacto ambiental: uma experiência em jornalismo ambiental", o coletor menstrual "proporciona melhorias tanto na vida e saúde feminina quanto ao meio ambiente. Para a mulher, permite maior liberdade, diminui as chances de alergias e problemas decorrentes da umidade na área da vagina, provocada pelo contato do sangue com a pele nos absorventes externos. Ao meio ambiente, ajuda na diminuição da produção de lixo e processos de degradação". Disponível em: <https://bit.ly/35STzIQ>. Acesso em 19 set. 2020.

${ }_{18}$ Considero a Diva como par mais experiente, com base nas interações ocorridas no grupo, na qual ela relatou que conseguiria elaborar a imagem da propaganda, apresentando uma postura de segurança e domínio das ferramentas de edição.
} 
da propaganda, as interações ocorridas no grupo apontam para a colaboração e incentivo à participação ativa das demais integrantes, com falas que buscam a opinião e validam o trabalho das demais colegas.

Após concordância das demais integrantes do grupo, Débora demonstra uma atitude proativa, ao propor fazer uma pesquisa no Google sobre essa questão, em 02/04/2019:

\begin{tabular}{l} 
Débora \\
vou pesquisar o que o google \\
diz....rs \\
\hline ada vez mais conhecido pelas \\
brasileiras, o coletor menstrual, \\
também chamado de copinho, \\
tem sido usado como alternativa \\
ecologicamente correta ao uso \\
de absorventes e também para \\
as mulheres que têm algum \\
tipo de alergia. O produto não é \\
novo, existe pelo menos desde \\
os anos 1960, é feito de silicone \\
medicinal, custa em média R\$ \\
100 e há fabricantes que indicam \\
uma duração de até 10 anos.
\end{tabular}

Figura 3. Excerto da fala da Débora sobre uma pesquisa no Google, em 02/04/2019. Fonte: Autoria própria, baseada na conversa do grupo do WhatsApp.

Por se tratar de um grupo composto por mulheres, o assunto presente na propaganda é comum à todas. Isto nos indica que os assuntos tratados, tanto em sala de aula, quanto em interações pessoais via grupo de WhatsApp despertam a atenção e participação das estudantes, a partir da identificação e aproximação com as suas vivências, de acordo com o relato da Débora, em 02/04/2019:

\begin{tabular}{|l|}
\hline É libertador de várias formas, \\
por não ter contato com algodão \\
e outras substâncias, por não \\
produzir lixo, por não provocar \\
calor que o absorvente provoca
\end{tabular}

Figura 4. Excerto da fala da Débora sobre a liberdade de usar coletor menstrual, em 02/04/2019.

Fonte: Autoria própria, baseada na conversa do grupo do WhatsApp.

Embora a negociação ocorrida no grupo seja em língua portuguesa (língua materna de todas as integrantes), a negociação sobre o texto em inglês procura seguir os aspectos léxico-gramaticais estudados em sala de aula e que se relacionam com o gênero discursivo "propaganda", com foco no uso do imperativo. Durante as interações, identificamos a Jéssica como um par mais experiente em língua 
inglesa, se colocando em uma posição de responsável pela elaboração de parte do texto em inglês, incluindo o uso desse modo verbal na língua-alvo, ao apontar as instruções de uso do coletor menstrual:

"Dobre na forma que preferir e se
sentir mais confortável"
Fold in the form that your prefer
and you feel more comfortable

Figura 5. Excerto da fala da Jéssica contendo instruções de uso do coletor menstrual, em 02/04/2019.

Fonte: Autoria própria, baseada na conversa do grupo do WhatsApp.

Ademais, Diva também busca aproximar a discussão da língua inglesa com a área da Administração e os recursos do Instagram, apontados em sala de aula como aspectos relevantes na divulgação de uma marca, como o uso de hashtags ${ }^{19}$ :

\begin{tabular}{|l|}
\hline Brand: TheSame \\
Target Audience: Women of \\
reproductive age \\
Campaign: \#TheSame \\
\#weareTheSame \\
\#TheSamesustainability $10: 26$ \\
\hline $\begin{array}{l}\text { E as hashtags, eu fiz trocadilhos } \\
\text { com a marca }\end{array}$ \\
\hline
\end{tabular}

Figura 6. Excerto da fala da Diva sobre as características da propaganda da marca "The Same", em 02/04/2019. Fonte: Autoria própria, baseada na conversa do grupo do WhatsApp.

A partir destes dados, podemos identificar interações colaborativas entre as estudantes, que resultam na construção de um grupo do aplicativo WhatsApp como um espaço de afinidade (GEE; HAYES, 2012), no qual há a ajuda mútua na elaboração da propaganda, seguindo os critérios estabelecidos pela professora, e com cada uma, dentro do seu conhecimento específico, contribuindo para a resolução da tarefa: a) Débora, com conhecimentos sobre higiene íntima feminina e sustentabilidade; b) Diva, com conhecimentos sobre edição de imagens e noções básicas de estratégias de Marketing Digital e c) Jéssica, responsável pela edição de parte da propaganda em inglês.

\footnotetext{
${ }^{19}$ As hashtags são palavras-chave precedidas pelo símbolo de jogo da velha (\#) bastante utilizadas em redes sociais e, segundo o site Canal Tech, "esse tipo de marcação (...) serve para associar uma informação a um tópico ou discussão. Geralmente essas hashtags tornam-se links indexáveis pelos mecanismos de busca. Isso permite que os demais usuários possam clicar nelas ou procurá-las e visualizarem todas as informações, imagens, vídeos etc relacionados a elas." Disponível em < https://canaltech.com.br/produtos/O-que-e-hashtag/>. Acesso em 19 set. 2020.
} 
É importante destacar que o sentimento de pertença é promovido dentro desse grupo, através de elogios ao trabalho das outras ${ }^{20}$, bem como este ser um aplicativo que não estabelece papeis fixos, como é observado em alguns ambientes virtuais de aprendizagem, onde uma pessoa se coloca em um papel de professora, outra de monitora e outras de estudantes, por exemplo. No caso dos dados analisados, a não participação da professora no grupo e a não obrigatoriedade de utilizar este aplicativo podem ter sido fatores que propiciaram uma liderança não fixa, ou nas palavras de Gee e Hayes (2012), uma liderança "porosa".

As Figuras 7 e 8 mostram o resultado final da postagem realizada pelo grupo analisado, na conta do Instagram da Turma A, cujos dizeres presentes na propaganda indicam, em tradução livre, "Nós podemos até ser diferentes..., mas o cuidado é o mesmo" e é seguido de instruções de uso elaborado pelas estudantes ${ }^{21}$. Além disso, a legenda da postagem ${ }^{22}$, feita em inglês e seguindo os critérios de avaliação, reforçam a questão da sustentabilidade em relação ao uso dos coletores menstruais, assunto bastante enfatizado ao longo da conversa do WhatsApp.

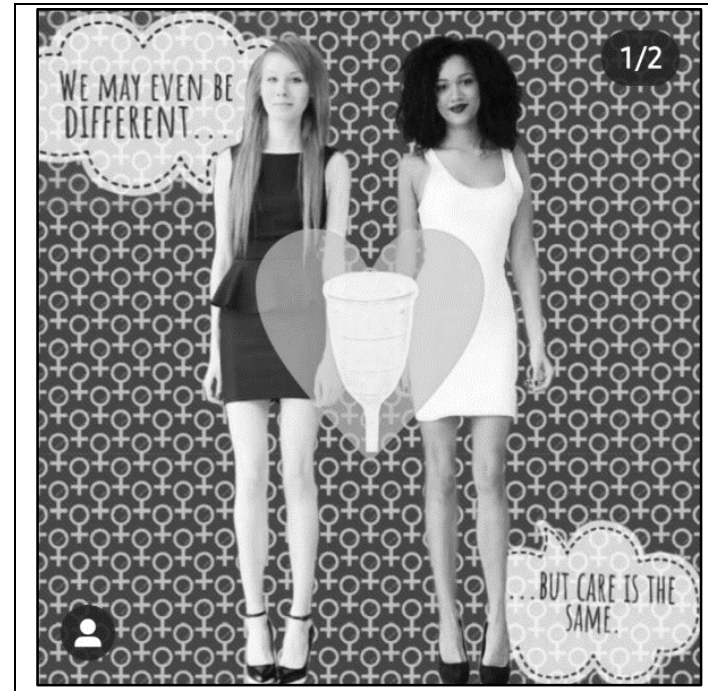

Figura 7. Primeira foto da propaganda da marca 'The Same".

Fonte: Instagram da turma A.

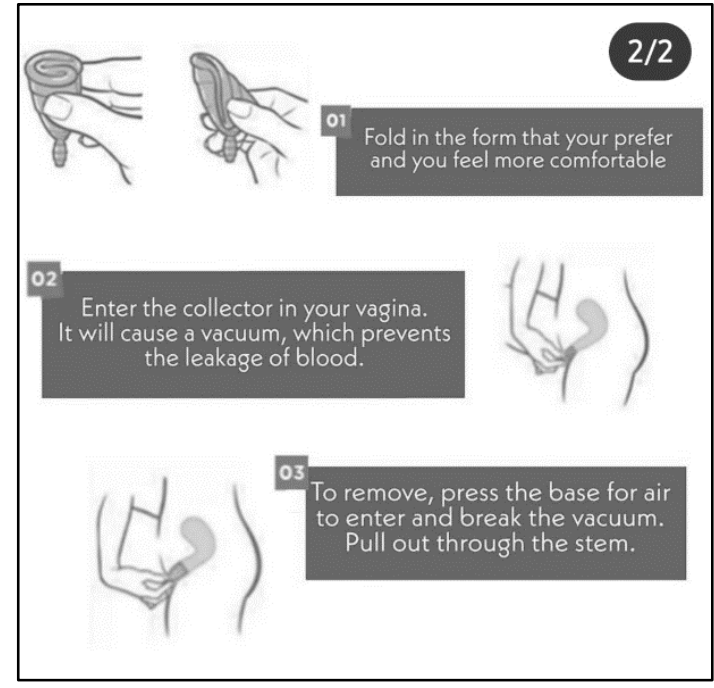

Figura 8. Segunda foto da propaganda da marca 'The Same".

Fonte: Instagram da turma A.

20 Um exemplo de elogio encontrado nas interações refere-se à fala da Jéssica sobre o trocadilho criado pela Diva, com relação ao uso do nome da marca "The Same" no slogan: "Q genial", em 02/04/2019.

${ }^{21}$ A tradução livre das instruções de uso indica: "01 Dobre na forma que você preferir e se sentir mais confortável", "02 Insira o coletor na sua vagina. Isto causará o vácuo, que evitará o vazamento de sangue" e "03 Para remover, pressione a base para 0 ar entrar e eliminar o vácuo. Retire pela haste". Possíveis desvios da norma padrão, na postagem das estudantes, podem ter sido causados devido ao uso do Google Tradutor.

22 A tradução livre da legenda da postagem indica: "Marca: The Same; Público-alvo: Mulheres em idade reprodutiva; Campanha: \#TheSame \#NósSomosTheSame \#TheSamesustabilidade; É cada vez mais conhecido pelas brasileiras o coletor menstrual, também chamado de copinho, que tem sido usado como uma alternativa ecologicamente correta aos absorventes e também por mulheres que têm alergias. O produto não é novo, ele existe desde os anos 60 , é feito de silicone medicinal e custa em torno de $\mathrm{R} \$ 100$ e há fabricantes que indicam que dure até 10 anos".

LínguaTec, Instituto Federal de Educação, Ciência e Tecnologia do Rio Grande do Sul, Bento Gonçalves v. 5 , n. 2, p. 208-226, nov. 2020. 
Finalizo esta análise de dados com o Quadro 5, que trata da visão das estudantes ${ }^{23}$ pesquisadas sobre 0 trabalho com temáticas nas aulas de Inglês Instrumental que perpassam a luta feminista e que buscam contribuir para uma sociedade menos preconceituosa e que valorize o papel das mulheres 24 :

Vanessa: com relação a esses assuntos abordados, mulheres no mercado de trabalho...

Jéssica: ... eu acho que você adivinha os assuntos, falava de mulher, disabilities ${ }^{25} \ldots$

Débora: na verdade, você foi a que mais enfatizou isso... e uma importância enorme, numa sala que só tem homens, e os homens tem que ser toda hora acordados...

Jéssica: ... a gente vive esses assuntos, e eles só ouvem sobre, né?

Quadro 5. Entrevista grupal realizada após o término do semestre letivo, em agosto de 2019.

Fonte: Autoria própria.

Percebemos, pois, na fala das estudantes a importância de se levar para a sala de aula assuntos que despertem a consciência crítica (HOOKS, 2015; 2017) não só de mulheres, mas também de homens, visto que as nossas práticas sociais são compostas por interações mediadas pelas linguagens e que, infelizmente, muitas vezes reforçam preconceitos e desigualdades de gênero e raça presentes na sociedade.

\section{Considerações finais}

Este trabalho apresentou parte de uma pesquisa desenvolvida em uma turma de um curso técnico em Administração, a qual promoveu, em sala de aula, a discussão sobre temas relevantes para a sociedade: a desigualdade de gênero, o racismo, entre outros. Ademais, buscou-se promover um ensino-aprendizagem de Inglês Instrumental que, a priori, seria meramente voltado para a compreensão de textos escritos, mas que foi além disso, ao propor, paralelamente às aulas presenciais, o uso de uma conta do Instagram para a publicação de posts feitos exclusivamente pelos estudantes da turma.

Após propor uma avaliação na disciplina de Inglês Instrumental, os caminhos percorridos por um grupo composto por três estudantes mulheres tiveram destaque na análise de dados, visto que

\footnotetext{
${ }^{23}$ Esta entrevista grupal foi realizada após o término do primeiro semestre de 2019, quando a disciplina de Inglês Instrumental já havia sido finalizada.

24 Destaco que também foi identificado em postagens de outros dois grupos uma postura politizada frente a valorização de corpos de mulheres negras e gordas, a partir de propagandas de marcas de roupas e de lingerie. Por limitações de espaço, esses dados não puderam ser inseridos neste artigo.

${ }^{25}$ A estudante fez referência a algumas aulas de Inglês Instrumental, na qual foram tratadas as questões de pessoas com necessidades específicas no mercado de trabalho.
} 
dialogavam, diretamente, com uma proposta de educação linguística feminista defendida aqui: partindo da consciência crítica (HOOKS, 2015; 2017) das educandas, esperava-se que houvesse a promoção do empoderamento (BERTH, 2019) e uma possível transformação social (FREIRE, 2019 [1968]).

O empoderamento apresentado nos dados diz respeito ao uso do coletor menstrual que traz benefícios tanto para a higiene íntima, quanto para o meio ambiente (GAYBOR, 2019). Ter consciência sobre as alternativas ao absorvente descartável é um fator que contribui para a promoção do direito humano à saúde menstrual digna e de quebra de tabus com relação a esse tema.

Com base nos dados apresentados, podemos identificar que 0 aplicativo WhatsApp foi considerado um espaço virtual de afinidade entre as integrantes do grupo, uma vez que as interações fomentavam o sentimento de pertença entre as estudantes. Assim, todas contribuiram, de certa forma, com a elaboração da tarefa avaliativa que consistia em criar uma propaganda de uma marca criada por elas, a "The Same", uma marca de coletores mentruais.

Por ser uma pesquisa situada em apenas uma turma e por um curto período de tempo, seria necessária uma pesquisa a longo prazo e com mais atores envolvidos para que pudéssemos identificar aspectos de transformação social na comunidade escolar como um todo. Entretanto, este trabalho tem 0 intuito de colaborar para futuras pesquisas em contextos semelhantes a este, e que se proponham a fomentar uma educação linguística feminista, para termos indivíduos mais empoderados, tendo como premissa Berth (2019) que nos lembra que

é o empoderamento um fator resultante da junção de indivíduos que se reconstroem e desconstroem em um processo contínuo que culmina em empoderamento prático da coletividade, tendo como resposta as transformações sociais que serão desfrutadas por todos e todas (p. 54).

\section{Referências}

DECLARAÇÃO UNIVERSAL DOS DIREITOS HUMANOS. Assembleia Geral das Nações Unidas em Paris. 1948. Disponível em: <https://nacoesunidas.org/wp-content/uploads/2018/10/DUDH.pdf>. Acesso em: 14 set. 2020.

GARCEZ, P. M. Regulamentação ética em pesquisa com seres humanos específica para as Ciências Humanas e Sociais no âmbito do Ministério da Saúde do Brasil: descaso, desconhecimento, confronto, diálogo e ruptura. 2015. Disponível em: <http://anpoll.org.br/portal/wp-content/uploads/2015/03/Garcezp-ANPOLL-\%C3\%A9tica-em-pesquisa-05.03.15.pdf>. Acesso em 14 set. 2020.

GAYBOR, J. Empowerment, destigmatization and sustainability: the co-construction of reusable menstrual technologies in the context of menstrual activism in Argentina. Gender, Technology and Development. United Kingdom, V. 23, n. 2, p. 111-129. 2019. https://doi.org/10.1080/09718524.2019.1643522 
GEE, J. P.; HAYES, E. Nurturing Affinity Spaces and Game-Based Learning. In: STEINKUEHLER, C.; SQUIRE, K.; BARAB, S. (Eds.). Games, Learning, and Society: Learning and Meaning in the Digital Age. Cambridge: Cambridge University Press, 2012.

GERHARDT, T. E.; SILVEIRA, D. T. Métodos de Pesquisa. Porto Alegre: Editora da UFRGS, 2009.

HOOKS, B. Feminism is for everybody. New York: Routledge, 2015.

HOOKS, B. Ensinando a transgredir: a educação como prática de liberdade. 2 ed. São Paulo: Editora WMF Martins Fontes, 2017.

LANGNER, A.; ZULIANI, C.; MENDONÇA, F. O movimento feminista e o ativismo digital: conquistas e expansão decorrentes do uso das plataformas online. In: Congresso Internacional de Direito e Contemporaneidade: mídias e direitos da sociedade em rede, 3., 2015. Santa Maria. Anais... Santa Maria: UFMS, 2011, p. 1-14.

LIMA, M. B.; DE GRANDE, P. B. Diferentes formas de ser mulher na hipermídia. In: ROJO, R. Escol@ conectada: os multiletramentos e as TICs. São Paulo: Parábola, 2013.

MOTA, V. M. "What's up with WhatsApp?": análise de interações em um grupo do aplicativo e a relação com a promoção da Autonomia na ensinagem de língua inglesa. Dissertação de mestrado, Programa Interdisciplinar de Pós-Graduação em Linguística Aplicada, Faculdade de Letras, Universidade Federal do Rio de Janeiro, 2017.

MOITA LOPES, L. P. Por uma Linguística Aplicada indisciplinar. São Paulo: Parábola Editorial, 2006.

RAMOS, R. C. G. Instrumental no Brasil: A desconstrução de mitos e a construção do futuro. In: FREIRE, M. M.; ABRAHÃO, M. H. V.; BARCELOS, A. M. F. (Orgs.). Linguística Aplicada e Contemporaneidade. São Paulo, SP: ALAB; Campinas, SP: Pontes Editores, 2005. p. 109-123.

RIBEIRO, D. Quem tem medo do feminismo negro? São Paulo: Companhia das Letras, 2018.

RIBEIRO, D. Lugar de fala. São Paulo: Pólen, 2019.

ROSSINI, A. M. Z. P.; BELMONTE, J. Panorama do ensino-aprendizagem de línguas para fins específicos: histórico, mitos e tendências. In: LIMA-LOPES, R. E.; FISCHER, C. R.; GAZOTTI-VALLIM, M. A. (Orgs.). Perspectivas em Línguas para Fins Específicos: Festschrift para Rosinda Ramos. Campinas, SP: Pontes Editores, 2015. p. 347-359.

SANTOS, B. S. A cruel pedagogia do vírus. São Paulo: Boitempo, 2020.

SILVA, I. P.; ROCHA, F. B. Implicações do uso do Whatsapp na educação. Revista EDaPECI São $\begin{array}{llllllll}\text { Cristóvão } & \text { (SE). } & \text { v.17. } & \text { n. } & 2, & \text { p. } & 161-174 & \text { mai./ago. }\end{array}$ https://doi.org/10.29276/redapeci.2017.17.25615.161-174

Data de submissão: 20/09/2020. Data de aprovação: 23/10/2020. 